\title{
Laparoscopic Versus Robot-Assisted Versus Transanal Low Anterior Resection: 3-Year Oncologic Results for a Population- Based Cohort in Experienced Centers
}

\author{
T. A. Burghgraef, MD ${ }^{1,2}$ (D) J. C. Hol, $\mathrm{MD}^{3,4}$, M. L. Rutgers, $\mathrm{MD}^{5}$, R. M. P. H. Crolla, MD ${ }^{6}$, \\ A. A. W. van Geloven, $\mathrm{MD}, \mathrm{PhD}^{7}$, R. Hompes, $\mathrm{MD}, \mathrm{PhD}^{5}$, J. W. A. Leijtens, $\mathrm{MD}, \mathrm{PhD}^{8}$, \\ F. Polat, MD, PhD ${ }^{12}$, A. Pronk, MD, $\mathrm{PhD}^{9}$, A. B. Smits, MD, $\mathrm{PhD}^{10}$, J. B. Tuynman, $\mathrm{MD}, \mathrm{PhD}^{4}$, \\ E. G. G. Verdaasdonk, MD, PhD $^{11}$, P. M. Verheijen, MD, PhD $^{1}$, C. Sietses, MD, $\mathbf{P h D}^{3}$, and \\ E. C. J. Consten, $\mathrm{MD}, \mathbf{P h D}^{1,2}$
}

${ }^{1}$ Department of Surgery, Meander Medical Center, Amersfoort, The Netherlands; ${ }^{2}$ Department of Surgery, University Medical Center Groningen, Groningen, The Netherlands; ${ }^{3}$ Department of Surgery, Hospital Gelderse Vallei, Ede, The Netherlands; ${ }^{4}$ Department of Surgery, Amsterdam UMC, Locatie VUmc, Amsterdam, The Netherlands; ${ }^{5}$ Department of Surgery, Amsterdam UMC, Locatie AMC, Amsterdam, The Netherlands; ${ }^{6}$ Department of Surgery, Amphia Hospital, Breda, The Netherlands; ${ }^{7}$ Department of Surgery, Tergooi Hospital, Hilversum, The Netherlands; ${ }^{8}$ Department of Surgery, Laurentius Hospital, Roermond, The Netherlands; ${ }^{9}$ Department of Surgery, Diakonessenhuis, Utrecht, The Netherlands; ${ }^{10}$ Department of Surgery, St. Antonius Hospital, Nieuwegein, The Netherlands; ${ }^{11}$ Department of Surgery, Jeroen Bosch Hospital, Den Bosch, The Netherlands; ${ }^{12}$ Department of Surgery, Canisius Wilhelmina Hospital, Nijmegen, The Netherlands

\begin{abstract}
Background. Laparoscopic, robot-assisted, and transanal total mesorectal excision are the minimally invasive techniques used most for rectal cancer surgery. Because data regarding oncologic results are lacking, this study aimed to compare these three techniques while taking the learning curve into account.

Methods. This retrospective population-based study cohort included all patients between 2015 and 2017 who underwent a low anterior resection at 11 dedicated centers that had completed the learning curve of the specific technique. The primary outcome was overall survival (OS) during a 3-year follow-up period. The secondary outcomes were 3-year disease-free survival (DFS) and 3-year local recurrence rate. Statistical analysis was performed using Cox-regression.
\end{abstract}

(C) The Author(s) 2021

First Received: 7 June 2021

Accepted: 31 August 2021;

Published Online: 4 October 2021

E. C. J. Consten, $\mathrm{MD}, \mathrm{PhD}$

e-mail: ecj.consten@meandermc.nl
Results. The 617 patients enrolled in the study included 252 who underwent a laparoscopic resection, 205 who underwent a robot-assisted resection, and 160 who underwent a transanal low anterior resection. The oncologic outcomes were equal between the three techniques. The 3 -year OS rate was $90 \%$ for laparoscopic resection, $90.4 \%$ for robot-assisted resection, and $87.6 \%$ for transanal low anterior resection. The 3-year DFS rate was $77.8 \%$ for laparoscopic resection, $75.8 \%$ for robot-assisted resection, and $78.8 \%$ for transanal low anterior resection. The 3 -year local recurrence rate was in $6.1 \%$ for laparoscopic resection, $6.4 \%$ for robot-assisted resection, and $5.7 \%$ for transanal procedures. Cox-regression did not show a significant difference between the techniques while taking confounders into account.

Conclusion. The oncologic results during the 3-year follow-up were good and comparable between laparoscopic, robot-assisted, and transanal total mesorectal technique at experienced centers. These techniques can be performed safely in experienced hands. 
The primary surgical treatment for rectal cancer is total mesorectal excision (TME). ${ }^{1}$ After the introduction of laparoscopic TME (L-TME), large randomized trials showed that oncologic outcomes for minimally invasive L-TME are not superior to open TME. ${ }^{2-5}$ However, because L-TME has led to an improvement in short-term outcomes such as hospital length of stay, ${ }^{6}$ it has become the standard technique in most Western countries. ${ }^{7}$

Despite its short-term benefits, laparoscopic surgery has not been proven superior to open surgery with regard to oncologic outcomes. ${ }^{2-5}$ Especially for distal tumors deep in the pelvis, the laparoscopic technique has technical limitations. To overcome these limitations, two new minimally invasive techniques have been introduced for the surgical resection of rectal carcinoma: robot-assisted TME (RTME) and transanal TME (TaTME).

Adequate comparative studies investigating L-TME, R-TME, and TaTME are lacking. Most studies are singlecenter cohort series reporting on the comparison of only two techniques, ${ }^{8}$ whereas studies comparing all three minimally invasive techniques are scarce. ${ }^{9}$ Additionally, most studies did not take into account the learning curve of the new technique, which is associated with worse outcomes. ${ }^{10,11}$ Despite the limited number of comparative studies, results show equality of the three techniques with regard to short-term results. ${ }^{8,11-13}$

Evidence regarding oncologic outcomes is scarce. Lately, case series have reported on the oncologic results of minimally invasive techniques for TME. High local recurrence rates have been found in series reporting on the initial cases managed using TaTME, leading to the suspension of TaTME in Norway. ${ }^{14,15}$ Similarly, a high local recurrence rate has been reported in a comparative study of R-TME. ${ }^{16}$ On the other hand, low local recurrence rates for both techniques have been reported as well. ${ }^{17-20}$

In conclusion, robust data comparing all three techniques regarding oncologic outcomes taking into account the learning curve are lacking. Therefore, this multicenter cohort study aimed to compare the 3-year oncologic outcomes of laparoscopic, robot-assisted, and transanal sphincter-saving TME performed by surgeons well beyond their learning curve.

\section{METHODS}

A retrospective multicenter cohort study was performed to compare L-TME with R-TME and TaTME performed in five dedicated laparoscopy centers, three dedicated robotassisted centers, and three dedicated TaTME centers between 2015 and 2017. A protocol regarding the design, methods, and statistical analysis was composed before initiation of the study. This study was reported in accordance with the Strengthening the Reporting of Observational Studies in Epidemiology (STROBE) guidelines. $^{21}$

\section{Design}

Centers were able to participate in this multicenter population-based cohort if they were "dedicated centers" for L-TME, R-TME, or TaTME and only one of the techniques was the standard technique. In addition, colorectal surgeons performing TME in the specific center had to be well beyond the learning curve for the specific technique, which is estimated to be about 40 procedures for R-TME and TaTME. ${ }^{22-25}$

The dedicated robot-assisted centers were three large teaching hospitals who started using R-TME in 2011, 2012, and 2014, respectively. The dedicated TaTME centers were three large teaching hospitals who started using TaTME in 2012, 2012, and 2014, respectively. With an average of 50 procedures per center annually and a maximum of two dedicated colorectal surgeons per center performing the procedure, it was estimated that all surgeons in the dedicated TaTME and robot-assisted centers that started using R-TME or TaTME in 2011 or 2012 were well beyond their learning curve at the beginning of the study. The two centers with start dates in 2014 fulfilled the learning curve in 2015. Therefore, in these centers, patients were included from 1 January 2016 until 31 December 2017. Finally, with more than 10 years of experience performing L-TME in the dedicated laparoscopic centers, these surgeons were estimated to be well beyond their learning curve as well. Altogether, 12 L-TME surgeons, 6 R-TME surgeons, and 6 TaTME surgeons participated in this study.

\section{Patients}

Patients were eligible for inclusion if they had a diagnosis of rectal cancer according to the new definition using the sigmoidal take-off on magnetic resonance imaging (MRI) or computed tomography (CT), ${ }^{26}$ were older than 18 years, were registered in the prospective Dutch ColoRectal Audit (DCRA), and had undergone an L-TME in a dedicated laparoscopic center, an R-TME in a dedicated robotassisted center, or a TaTME in a dedicated TaTME center. Patients were excluded if they had undergone surgery in an emergency setting, had a synchronous metastasis during diagnosis of rectal cancer, had undergone treatment with palliative intent, had more than one colorectal tumor at diagnosis, had undergone hyperthermic intraperitoneal chemotherapy (HIPEC) or intraoperative radiotherapy (IORT), had undergone transanal minimally invasive surgery (TAMIS), had undergone an abdominal perineal 
resection (APR), or had a surgeon performing the procedure who did not fulfil the learning curve. Each patient was discussed by a local multidisciplinary cancer board, and neoadjuvant treatment was offered according to the current Dutch National guidelines for colorectal cancer. ${ }^{27}$

\section{Outcomes}

The primary outcome was overall survival (OS) after the 3-year follow-up period. Overall survival was defined as being alive at the 3-year follow-up evaluation. The secondary outcomes were disease-free survival (DFS) after the 3-year follow-up period, systemic recurrence after the 3-year follow-up period, local recurrence after the 3-year follow-up period, pattern of local recurrence, location of distant metastasis, and permanent stoma rate at the end of the follow-up period. Disease-free survival was defined as being alive without recurrent disease after the 3-year follow-up period. Systemic recurrence was defined as any distant metastasis, either pathologically proven or considered to be a lesion suspect for metastasis on imaging that showed growth on consecutive imaging. Local recurrence was defined as a tumor deposit located in the pelvic cavity, with pathologically proven adenocarcinoma or growth on consecutive imaging if histopathologic confirmation was absent. Multifocal local recurrence was defined as two or more separate deposits of recurrence in the pelvis. Location of local recurrence was classified according to the classification by Georgiou et al. ${ }^{28}$

The baseline characteristics were age, sex, body mass index (BMI), American Society of Anesthesiologists (ASA) classification, history of abdominal surgery, distance of the tumor from the anorectal junction (ARJ) on MRI, low defined rectal tumor according to the English National Low Rectal Cancer Development Programme (LOREC) ${ }^{29}$ mesorectal fascia involvement (MRF) on preoperative MRI, neoadjuvant (chemo)radiation therapy, preoperative tumor-node-metastasis (TNM) classification, and type of procedure (low anterior resection [LAR] with end colostomy or LAR with primary anastomosis). Furthermore, pathologic TNM classification, histologic tumor type, positive circumferential resection margin $(\leq 1 \mathrm{~mm})$, quality of the TME specimen according to Quirke, ${ }^{30}$ 30-day postoperative mortality, 30-day surgical complications graded according to the Clavien-Dindo classification, ${ }^{31}$ and anastomotic leakage rate at the end of the follow-up period according to the definition of the International Study Group of Rectal Cancer $^{32}$ were registered.

\section{Data Sources}

All the hospitals provided their local DCRA data, including the unique patient number. After pseudonymisation, missing and incomplete data were added in the database by accessing the electronical medical record (EMR) of the local hospitals. In addition, local recurrence, systemic recurrence, survival data, and follow-up data were added using the EMR of the local hospitals. All preoperative MRI data were reviewed by trained researchers. Informed consent was deemed unnecessary according to the Dutch Medical Treatment Agreement Act. The regional medical ethical committee and local ethical committees of all the hospitals gave approval for the study (MEC-U, AW19.023 W18.100).

\section{Statistical Methods}

Categorical data are presented as number and percentages. Continuous variables are presented as mean and standard deviation or median and interquartile range (IQR) depending on the distribution. Survival curves of the patients were plotted in Kaplan-Meier graphs. To control for confounding factors that might have influenced choice of the surgical technique, a Cox regression using a backward model was performed comparing the three techniques for 3-year overall-survival, 3-year DFS, 3-year local recurrence, and 3-year systemic recurrence. For the Cox regressions, missing data were imputed using multiple imputation if the type of the missing data was missing at random or missing completely at random.

The variables used in the Cox regression were age (continuous), sex, BMI (continuous), history of abdominal surgery, ASA classification (1/3 vs $3 / 4)$, distance of the tumor to the ARJ on MRI in centimeters (continuous), neoadjuvant (chemo)radiation therapy, and a variable combining clinical $\mathrm{T}$ stage and MRF involvement on preoperative MRI. This variable was graded as cT3 without MRF involvement, cT3 with MRF involvement, cT4a or cT4b. Whereas cT4a was defined as a tumor invading in the ventral peritoneum, cT4b was defined as a tumor invading the sphincter complex or an adjacent organ.

The regression models were evaluated for assumptions and adjusted if necessary. Hazard ratios (HRs) and $p$ values were used to interpret the results. A confidence interval either below or above 1 was interpreted as significant. Analyses were performed with $\mathrm{R}$ (version 3.6.1) using the "survival" and "survminer" packages. 


\section{RESULTS}

The study identified 1834 patients as eligible between 1 January 2015 and 31 December 2017. After excluding 764 patients, the study had 1070 candidate patients. Of these patients, 487 had surgery in a dedicated laparoscopy center, 340 had surgery in a dedicated robot-assisted center, and 243 had surgery in a dedicated TaTME center. Additionally, 153 patients had a resection performed by a technique that was not the standard technique of the dedicated center, and 300 patients underwent an abdominoperineal resection (APR) and were therefore excluded from the study.

Finally, 617 patients who underwent a low anterior resection (LAR) in a dedicated center were included in the analysis comprising 252 laparoscopic (L-LAR), 205 robotassisted (R-LAR), and 160 TaTME procedures (Fig. 1). Abdominal perineal resection was performed for 202 patients $(41.5 \%)$ in a laparoscopy center, for 106 patients $(31.2 \%)$ in a robot-assisted center, and for 60 patients $(24.7 \%)$ in a TaTME center. In the laparoscopy centers 56 (11.4\%) patients did not undergo TME by the dedicated technique, and $27(5.5 \%)$ of these patients underwent an open resection. In the robot-assisted and TaTME centers, respectively $34(10.0 \%)$ and $62(25.5 \%)$ patients did not undergo the dedicated technique, and respectively $5(1.5 \%)$ and $8(3.2 \%)$ of these patients underwent an open resection.

\section{Patient Characteristics}

The mean patient age was higher in the laparoscopic L-LAR group than in the R-LAR and TaTME groups ( $68 \pm$ 9.7 years vs. $66 \pm 10.2$ and $65 \pm 10.9$ years; $p=0.04$ ).
Data regarding race were not provided in the dataset. The median tumor distance from the ARJ on MRI was significantly greater in the L-LAR and R-LAR groups than in the TaTME group $(7 \pm 5.9$ and $8 \pm 6.9 \mathrm{~cm}$ vs. $4 \pm 3.6 \mathrm{~cm} ; p<$ $0.001)$. The L-LAR group had significantly less mesorectal fascia involvement than the R-LAR and TaTME groups ( $17.1 \%$ vs. $26.4 \%$ and $28.9 \%$; $p=0.009$ ). Furthermore, significantly fewer primary anastomoses were constructed in the L-LAR group than in the R- LAR and TaTME groups $(68.3 \%$ vs. $91.2 \%$ and $82.5 \% ; p<0.001)$. Additionally, a significantly higher permanent stoma rate at the end of the follow-up period was observed in the L-TME group than in the R-TME and TaTME groups $(42.1 \%$ vs. $22.0 \%$ and $31.2 \%$ ) (Tables 1 and 2). Finally, the positive circumferential rate was $2.7 \%$ in the L-LAR group, $4.5 \%$ in the R-LAR group, and $3.2 \%$ in the TaTME group $(p=$ $0.58)$.

\section{Overall Survival}

The OS rate during the 3-year follow-up period was $90.0 \%$ in the L-LAR group, $90.4 \%$ in the R-LAR group, and $87.6 \%$ in the TaTME group (Table 2; Fig. 2). Cox regression did not show an association of the surgical technique with OS (Table 3). The factors associated with worse OS were age (HR 1.03; 95\% confidence interval [CI], 1.00-1.06), ASA 3 and 4 (HR 6.63; 95\% CI 3.66-12.0), cT3 MRF-tumor (HR, 2.05; 95\% CI 1.01-4.16), and cT4b tumor (HR 6.77; 95\% CI 2.04-22.4). Increased distance of the tumor to the ARJ was associated with improved OS (HR 0.88; 95\% CI 0.79-0.98) (Table 3).
FIG. 1 Flow diagram of patients included in the study. DCRA Dutch Colorectal Audit, TME total mesorectal excision, $L A R$ low anterior resection, Lap laparoscopic, Robot robotassisted, TaTME transanal TME, HIPEC hyperthermal intraperitoneal chemotherapy, IORT intraoperative radiotherapy, TEM transanal endoscopic microsurgery, $A P R$ abdominoperineal resection. 1 Patients who underwent surgery in 2015 at a TaTME or robotassisted center that started performing TaTME or robotassisted TME respectively in 2014

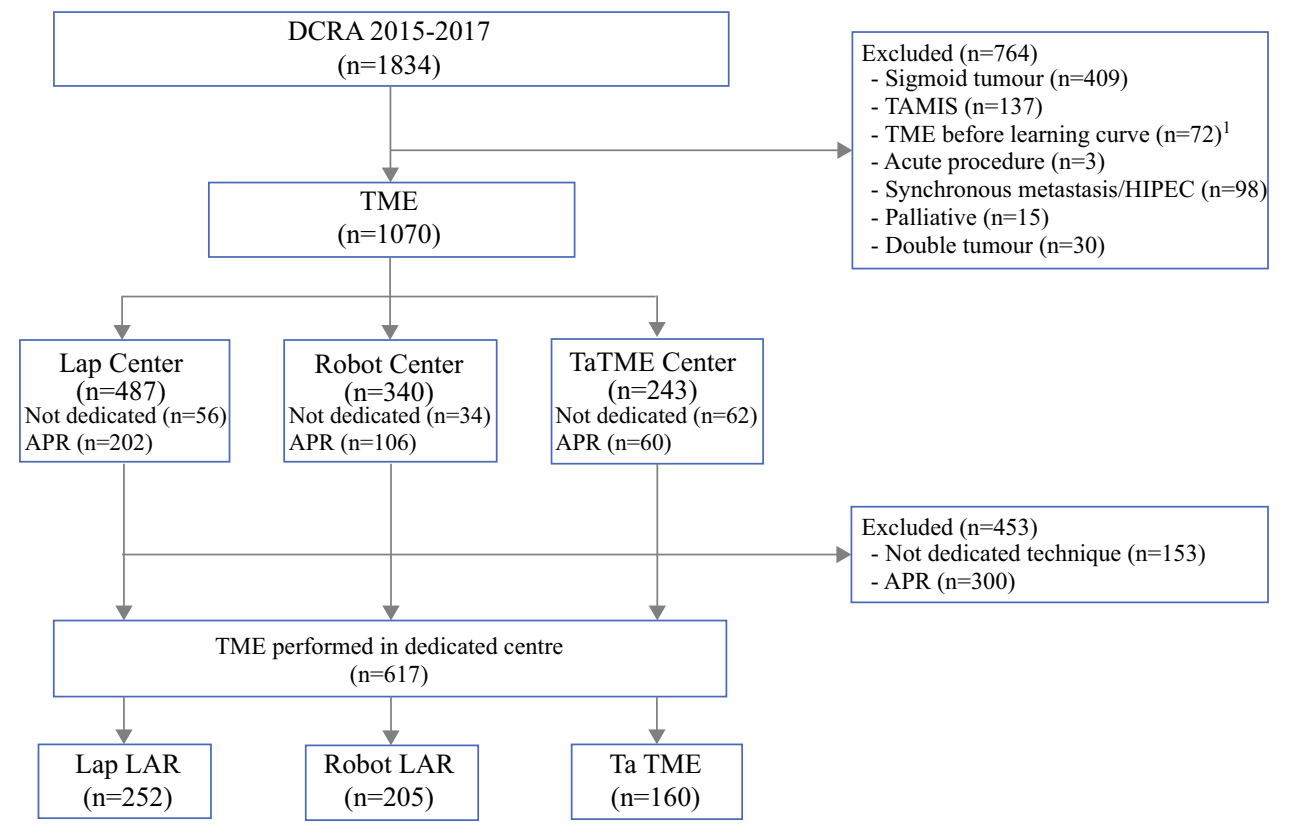


TABLE 1 Baseline characteristics

\begin{tabular}{|c|c|c|c|c|c|}
\hline & & $\begin{array}{l}\text { L-LAR } \\
(n=252) \\
n(\%)\end{array}$ & $\begin{array}{l}\text { R-LAR } \\
(n=205) \\
n(\%)\end{array}$ & $\begin{array}{l}\text { TaTME } \\
(n=160) \\
n(\%)\end{array}$ & $p$ Value \\
\hline Mean age (years) & & $68 \pm 9.7$ & $66 \pm 10.2$ & $65 \pm 10.9$ & 0.04 \\
\hline Mean BMI $\left(\mathrm{kg} / \mathrm{m}^{2}\right)$ & & $26 \pm 4.4$ & $26 \pm 3.8$ & $26 \pm 4.3$ & 0.87 \\
\hline \multirow[t]{2}{*}{ Sex } & Male & $155(61.5)$ & $128(62.4)$ & $111(69.4)$ & 0.24 \\
\hline & Female & $97(38.5)$ & 77 (37.6) & $49(30.6)$ & \\
\hline \multirow[t]{4}{*}{ ASA classification } & 1 & $59(23.4)$ & $45(22.0)$ & 35 (21.9) & 0.67 \\
\hline & 2 & $137(54.4)$ & $123(60.0)$ & $95(59.4)$ & \\
\hline & 3 & $53(21.0)$ & $37(18.0)$ & $29(18.1)$ & \\
\hline & 4 & $3(1.2)$ & $0(0.0)$ & $1(0.6)$ & \\
\hline History of abdominal surgery & & $79(31.3)$ & $46(22.4)$ & $37(23.1)$ & 0.06 \\
\hline Median distance tumor to ARJ: $\mathrm{cm}$ (IQR) & & $7(5-9)$ & $8(6-9)$ & $4[3,6]$ & $<0.001$ \\
\hline \multirow[t]{2}{*}{ Low defined tumor ${ }^{\mathrm{a}}$} & Yes & $110(44.2)$ & $69(34.5)$ & $80(50.0)$ & 0.01 \\
\hline & Missing & $3(1.2)$ & $5(2.4)$ & $0(0.0)$ & \\
\hline \multirow[t]{2}{*}{ Mesorectal fascia involvement on preoperative MRI } & $\mathrm{MRF}+$ & $43(17.1)$ & $53(26.4)$ & $46(28.9)$ & 0.009 \\
\hline & Missing & $0(0.0)$ & $5(2.4)$ & $1(0.6)$ & \\
\hline \multirow[t]{6}{*}{$\mathrm{cT}$} & 1 & $7(2.8)$ & $5(2.4)$ & $6(3.8)$ & 0.69 \\
\hline & 2 & $80(31.7)$ & $66(32.2)$ & $42(26.4)$ & \\
\hline & 3 & $156(61.9)$ & $117(57.1)$ & $104(65.4)$ & \\
\hline & $4 \mathrm{a}$ & $4(1.6)$ & $9(4.3)$ & $2(1.3)$ & \\
\hline & $4 \mathrm{~b}$ & $5(2.0)$ & $7(3.4)$ & $5(3.1)$ & \\
\hline & Missing & $0(0.0)$ & $1(0.5)$ & $1(0.6)$ & \\
\hline \multirow[t]{4}{*}{$\mathrm{cN}$} & 0 & $108(42.9)$ & $87(42.4)$ & $86(53.8)$ & 0.04 \\
\hline & 1 & $88(34.9)$ & $68(33.2)$ & $54(33.8)$ & \\
\hline & 2 & $56(22.2)$ & $50(24.4)$ & $20(12.5)$ & \\
\hline & Missing & $0(0.0)$ & $1(0.5)$ & $0(0.0)$ & \\
\hline \multirow[t]{4}{*}{ Neoadjuvant therapy } & None & $109(44.0)$ & $82(40.4)$ & $64(40.0)$ & 0.46 \\
\hline & Radiotherapy & $83(33.5)$ & $69(34.0)$ & $47(29.4)$ & \\
\hline & Chemoradiation & $56(22.6)$ & $52(25.6)$ & $49(30.6)$ & \\
\hline & Missing & $4(1.6)$ & $2(1.0)$ & $0(0.0)$ & \\
\hline \multirow[t]{2}{*}{ Procedure } & LAR + colostomy & $80(31.7)$ & $18(8.8)$ & $28(17.5)$ & $<0.001$ \\
\hline & LAR + anastomosis & $172(68.3)$ & $187(91.2)$ & $132(82.5)$ & \\
\hline \multirow[t]{3}{*}{ Histologic type } & Adenocarcinoma & $240(95.2)$ & $196(95.6)$ & 155 (96.9) & 0.38 \\
\hline & Mucinous & $12(4.8)$ & $9(4.4)$ & $4(2.5)$ & \\
\hline & Other & $0(0.0)$ & $0(0.0)$ & $1(0.6)$ & \\
\hline \multirow[t]{3}{*}{ Differentiation } & Well/moderate & $233(92.5)$ & $184(89.8)$ & $146(91.2)$ & 0.90 \\
\hline & Poor & $7(2.8)$ & $7(3.4)$ & $5(3.1)$ & \\
\hline & Unknown & $12(4.8)$ & $14(6.8)$ & $9(5.6)$ & \\
\hline \multirow[t]{6}{*}{ pT } & 0 & $15(6.0)$ & $14(6.9)$ & $15(9.4)$ & 0.49 \\
\hline & 1 & $28(11.2)$ & $25(12.3)$ & $22(13.8)$ & \\
\hline & 2 & $99(39.4)$ & $66(32.4)$ & $55(34.6)$ & \\
\hline & 3 & 107 (42.6) & $93(45.6)$ & $64(40.3)$ & \\
\hline & 4 & $2(0.8)$ & $6(2.9)$ & $3(1.9)$ & \\
\hline & Missing & $1(0.4)$ & $2(1.0)$ & $1(0.6)$ & \\
\hline \multirow[t]{4}{*}{$\mathrm{pN}$} & 0 & $166(65.9)$ & $136(66.7)$ & $114(71.2)$ & 0.60 \\
\hline & 1 & $61(24.2)$ & $47(23.0)$ & $28(17.5)$ & \\
\hline & 2 & $25(9.9)$ & $21(10.3)$ & $18(11.2)$ & \\
\hline & Missing & $0(0.0)$ & $1(0.5)$ & $1(0.6)$ & \\
\hline $\mathrm{CRM}^{\mathrm{b}}$ & $(\leq 1 \mathrm{~mm})$ & $4(1.7)$ & $9(4.7)$ & $4(2.8)$ & 0.18 \\
\hline
\end{tabular}


Table 1 (continued)

\begin{tabular}{|c|c|c|c|c|c|}
\hline & & $\begin{array}{l}\text { L-LAR } \\
(n=252) \\
n(\%)\end{array}$ & $\begin{array}{l}\text { R-LAR } \\
(n=205) \\
n(\%)\end{array}$ & $\begin{array}{l}\text { TaTME } \\
(n=160) \\
n(\%)\end{array}$ & $p$ Value \\
\hline & Missing & $1(0.4)$ & $2(1.0)$ & $1(0.6)$ & \\
\hline \multirow[t]{2}{*}{ Incomplete TME specimen } & & $7(2.9)$ & $9(4.4)$ & $2(1.3)$ & 0.23 \\
\hline & Missing & $8(3.2)$ & $1(0.5)$ & $5(3.1)$ & \\
\hline \multirow[t]{2}{*}{ 30-Day surgical complications } & & $83(32.9)$ & $82(40.0)$ & $49(30.6)$ & 0.15 \\
\hline & $\mathrm{CD} \geq 3$ & $53(21.0)$ & $43(21.0)$ & $40(25.0)$ & 0.58 \\
\hline Anastomotic leakage $^{c}$ & & $30(11.9)$ & $33(16.0)$ & $26(16.2)$ & 0.85 \\
\hline 30-Day mortality & & $4(1.6)$ & $3(1.5)$ & $0(0.0)$ & 0.29 \\
\hline
\end{tabular}

$L-L A R$ laparoscopic low anterior resection, $R$-LAR robot-assisted low anterior resection, TaTME transanal total mesorectal excision, $B M I$ body mass index, ASA American Society of Anesthesiologists, $A R J$ anorectal junction, $I Q R$ interquartile range, MRI magnetic resonance imaging, $M R F$ mesorectal fascia involvement, $C R M$ circumferential resection margin, $T M E$ total mesorectal excision, $C D$ Clavien-Dindo classification grade

${ }^{1}$ Defined according to the English National Low Rectal Cancer Development Programme (LOREC)

${ }^{\mathrm{b}}$ Positive CRM rate as percentage of patients with ypT1-4

${ }^{\mathrm{c}}$ Anastomotic leakage as percentage of LAR with primary anastomosis

TABLE 2 Oncologic results not corrected for preoperative characteristics

\begin{tabular}{|c|c|c|c|c|c|}
\hline & & $\begin{array}{l}\text { L-LAR } \\
(n=252) \\
n(\%)\end{array}$ & $\begin{array}{l}\text { R-LAR } \\
(n=205) \\
n(\%)\end{array}$ & $\begin{array}{l}\text { TaTME } \\
(n=160) \\
n(\%)\end{array}$ & $p$ Value \\
\hline \multicolumn{2}{|c|}{ Median follow-up: months (IQR) } & $36(25-46)$ & $37(26-45)$ & $35[25,45]$ & 0.83 \\
\hline \multicolumn{2}{|c|}{ 3-Year overall survival } & $159(90.0)$ & $124(90.4)$ & $82(87.6)$ & 0.90 \\
\hline \multicolumn{2}{|l|}{ 3-Year disease-free survival } & $121(77.8)$ & $97(75.8)$ & $73(78.8)$ & 0.76 \\
\hline \multirow[t]{8}{*}{ 3-Year local recurrence } & & $12(6.1)$ & $12(6.4)$ & $7(5.7)$ & 0.82 \\
\hline & Anterior & $0(0.0)$ & $1(0.5)$ & $0(0.0)$ & \\
\hline & Lateral & $3(1.1)$ & $1(0.5)$ & $1(0.6)$ & \\
\hline & Inferior & $5(2.0)$ & $2(1.0)$ & $0(0.0)$ & \\
\hline & Central anastomotic & $2(0.8)$ & $5(2.4)$ & $3(1.9)$ & \\
\hline & Central non-anastomic & $6(2.4)$ & $6(2.9)$ & $0(0.0)$ & \\
\hline & Peritoneal refletion & $1(0.4)$ & $0(0.0)$ & $0(0.0)$ & \\
\hline & Multifocal recurrence & $1(7.1)$ & $3(18.8)$ & $0(0.0)$ & 0.47 \\
\hline \multirow[t]{8}{*}{ 3-Year systemic recurrence } & & $32(15.1)$ & $28(15.9)$ & $15(10.1)$ & 0.43 \\
\hline & Liver & $21(8.3)$ & $13(6.3)$ & $8(5.0)$ & \\
\hline & Lung & $17(6.7)$ & $14(6.8)$ & $8(5.0)$ & \\
\hline & Peritoneal & $3(1.2)$ & $5(2.4)$ & $2(1.2)$ & \\
\hline & Bone & $1(0.4)$ & $2(1.0)$ & $2(1.2)$ & \\
\hline & Ovary & $1(0.4)$ & $0(0.0)$ & $0(0.0)$ & \\
\hline & Brain & $1(0.4)$ & $0(0.0)$ & $0(0.0)$ & \\
\hline & Other & $4(1.6)$ & $2(1.0)$ & $4(2.5)$ & \\
\hline \multicolumn{2}{|l|}{ Permanent stoma rate ${ }^{a}$} & $106(42.1)$ & $45(22.0)$ & $50(31.2)$ & $<0.001$ \\
\hline
\end{tabular}

L-LAR laparoscopic low anterior resection, $R$-LAR robot-assisted low anterior resection, TaTME transanal total mesorectal excision, $I Q R$ interquartile range

${ }^{a}$ Permanent stoma rate at the end of the follow-up period 

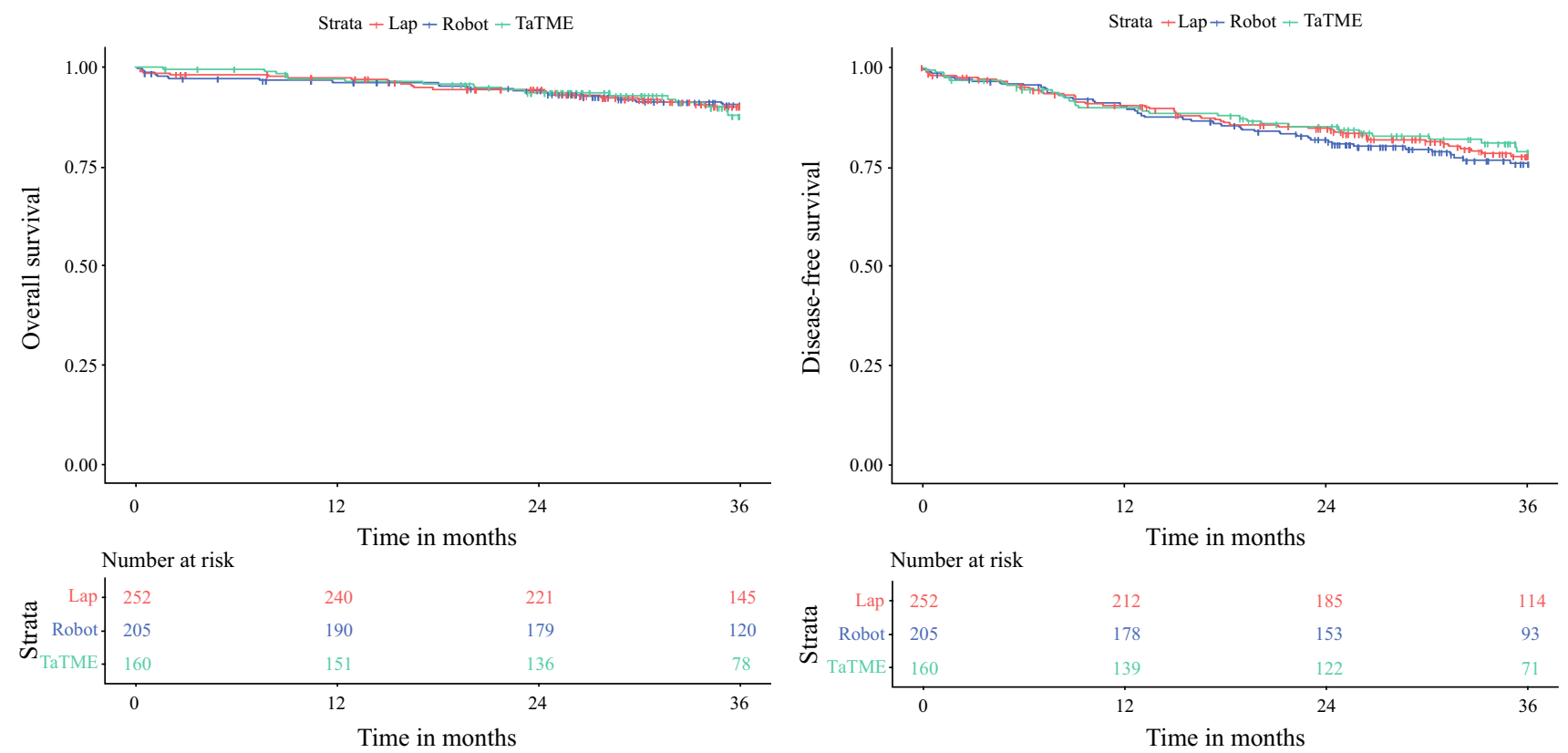

FIG. 2 Curves showing 3-year overall and disease-free survival. Lap laparoscopic low anterior resection, Robot robot-assisted low anterior resection, TaTME transanal total mesorectal excision

TABLE 3 Cox regression of 3-year overall survival (OS) and disease-free survival (DFS)

\begin{tabular}{|c|c|c|c|c|c|c|c|}
\hline & & \multicolumn{3}{|c|}{ 3-Year OS } & \multicolumn{3}{|c|}{ 3-Year DFS } \\
\hline & & HR & $95 \% \mathrm{CI}$ & $p$ Value & HR & $95 \% \mathrm{CI}$ & $p$ Value \\
\hline \multirow[t]{3}{*}{ Approach } & L-LAR & - & - & - & - & - & - \\
\hline & R-LAR & 1.31 & $(0.69-2.50)$ & 0.42 & 1.18 & $(0.78-1.79)$ & 0.44 \\
\hline & TaTME & 0.78 & $(0.37-1.63)$ & 0.50 & 0.75 & $(0.45-1.28)$ & 0.29 \\
\hline Age & & 1.03 & $(1.00-1.06)$ & 0.05 & 1.00 & $(0.99-1.02)$ & 0.65 \\
\hline BMI $\left(\mathrm{kg} / \mathrm{m}^{2}\right)$ & & 0.99 & $(0.94-1.05)$ & 0.76 & 0.98 & $(0.94-1.02)$ & 0.32 \\
\hline Sex & Male & 1.10 & $(0.59-2.03)$ & 0.75 & 1.33 & $(0.89-1.99)$ & 0.16 \\
\hline ASA classification & $3 / 4$ & 6.62 & $(3.66-12.0)$ & $<0.001$ & 2.82 & $(1.86-4.28)$ & $<0.001$ \\
\hline History of abdominal surgery & Yes & 0.93 & $(0.51-1.72)$ & 0.83 & 1.26 & $(0.83-1.91)$ & 0.27 \\
\hline Distance tumor to ARJ & & 0.88 & $(0.79-0.98)$ & 0.02 & 0.94 & $(0.88-1.02)$ & 0.12 \\
\hline \multirow[t]{4}{*}{$\mathrm{cT} / \mathrm{MRF}$} & cT3, MRF- & 2.05 & $(1.01-4.16)$ & 0.05 & 1.76 & $(1.07-2.90)$ & 0.03 \\
\hline & cT3, MRF+ & 0.84 & $(0.31-2.32)$ & 0.74 & 1.23 & $(0.64-2.35)$ & 0.53 \\
\hline & cT4a & 1.53 & $(0.31-7.42)$ & 0.60 & 3.16 & $(1.23-8.14)$ & 0.02 \\
\hline & $\mathrm{cT} 4 \mathrm{~b}$ & 6.77 & (2.04-22.4) & 0.001 & 7.89 & $(3.62-17.2)$ & $<0.001$ \\
\hline $\mathrm{cN}$ & $\mathrm{cN}+$ & 0.91 & $(0.39-2.12)$ & 0.83 & 0.84 & $(0.49-1.44)$ & 0.53 \\
\hline Neoadjuvant therapy & Yes & 1.11 & $(0.45-2.73)$ & 0.83 & 1.25 & $(0.69-2.26)$ & 0.46 \\
\hline
\end{tabular}

$H R$ hazard ratio, $C I$ confidence interval, $L-L A R$ laparoscopic low anterior resection, $R$-LAR robot-assisted low anterior resection, TaTME transanal total mesorectal excision, $B M I$ body mass index, $O R$ odds ratio, $B M I$ body mass index, $A S A$ American society of anesthesiologists, $A R J$ anorectal junction

\section{Disease-Free Survival}

The DFS rate during the 3-year follow-up period was $77.8 \%$ in the L-LAR group, $75.8 \%$ in the R-LAR group, and $78.8 \%$ in the TaTME group (Table 2; Fig. 2). Cox regression did not show an association of the surgical technique with DFS. The factors associated with worse DFS were ASA 3 and 4 (HR 2.82; 95\% CI 1.86-4.28), cT3 MRF-tumor (HR 1.76; 95\% CI 1.07-2.90), cT4a tumor 
(HR 3.16; 95\% CI 1.23-8.14), and cT4b tumor (HR 7.89; 95\% CI 3.62-17.2) (Table 2).

\section{Local Recurrence}

The local recurrence rate was $6.1 \%$ in the L-LAR group, $6.4 \%$ in the R-LAR group, and $5.7 \%$ in the TaTME group during the 3-year follow-up period. Multifocal recurrence was seen in $1(7.1 \%)$ of 12 laparoscopic patients, $3(18.8 \%)$ of 13 robot-assisted patients, and none of the TaTME patients (Table 2). Cox regression did not show an association of the surgical technique with local recurrence. The factors associated with local recurrence at 3 years were cT4a tumor (HR 11.58; 95\% CI 2.40-55.8) and cT4b tumor (HR 12.94; 95\% CI 2.64-64.0) (Table 4).

\section{DISCUSSION}

This study compared 3-year oncologic outcomes between L-LAR, R-LAR, and TaTME in dedicated centers while taking the learning curve into account. The results from this study showed equal oncologic outcomes for all three minimally invasive techniques. Comparable OS, DFS, local recurrence, and systemic recurrence were observed during the 3-year follow-up period. To our knowledge this is the first study to compare all three minimally invasive techniques performed by surgeons well beyond the learning curve of each specific technique, with the longest follow-up data presented to date.

The OS survival rates at 3 years in this study were $90.0 \%$ for the laparoscopic, $90.4 \%$ for the robot-assisted, and $87.6 \%$ for the TaTME technique. The corresponding DFS rates at 3 years were $77.8 \%, 75.8$ and $78.8 \%$. For both outcomes, no difference between the three techniques was observed in the multivariable Cox regression. First, these results showed the high quality of oncologic outcomes in the dedicated centers, underscoring our assumption that the included centers were dedicated and beyond the learning curve for the specific technique. The aforementioned rates are comparable with those of large trials comparing L-TME with open TME such as the AlaCaRT, ACOSOG Z6501, COREAN and COLOR II trials. ${ }^{2,4,5,33}$ All these trials used strict inclusion criteria and excluded ASA 4 patients or cT4 tumors. In contrast, the current populationbased cohort presents a more realistic image of clinical practice, with better external validity than the randomized clinical trials.

Second, these results show comparable oncologic outcomes among all three techniques. This is the first analysis to compare all three techniques. To date, no comparative oncologic data regarding TaTME have been published. Retrospective cohort analyses regarding TaTME show a similar OS rate. ${ }^{19,20}$ Studies comparing oncologic results after R-TME with L-TME are scarce, but mainly confirm

TABLE 4 Cox regression of 3-year local recurrence and 3-year systemic recurrence

\begin{tabular}{|c|c|c|c|c|c|c|c|}
\hline & & \multicolumn{3}{|c|}{ 3-year Local recurrence } & \multicolumn{3}{|c|}{ 3-year Systemic recurrence } \\
\hline & & HR & $95 \% \mathrm{CI}$ & $p$ value & HR & $95 \% \mathrm{CI}$ & $p$ value \\
\hline \multirow[t]{3}{*}{ Approach } & L-LAR & - & - & - & - & - & - \\
\hline & R-LAR & 1.25 & $(0.54 ; 2.86)$ & 0.60 & 1.03 & $(0.61 ; 1.73)$ & 0.91 \\
\hline & TaTME & 0.51 & $(0.17 ; 1.51)$ & 0.23 & 0.74 & $(0.37 ; 1.49)$ & 0.40 \\
\hline Age & & 1.00 & $(0.96 ; 1.03)$ & 0.81 & 0.99 & $(0.97 ; 1.01)$ & 0.34 \\
\hline BMI (kg/m2) & & 1.03 & $(0.95 ; 1.12)$ & 0.46 & 1.02 & $(0.96 ; 1.08)$ & 0.57 \\
\hline Sex & Male & 1.74 & $(0.75 ; 4.06)$ & 0.20 & 1.29 & $(0.78 ; 2.13)$ & 0.32 \\
\hline ASA classification & $3 / 4$ & 1.98 & $(0.79 ; 4.95)$ & 0.15 & 1.48 & $(0.81 ; 2.71)$ & 0.20 \\
\hline History of abdominal surgery & Yes & 1.04 & $(0.43 ; 2.53)$ & 0.92 & 1.81 & $(1.08 ; 3.02)$ & 0.02 \\
\hline Distance tumour to ARJ & & 0.88 & $(0.76 ; 1.02)$ & 0.08 & 1.01 & $(0.93 ; 1.11)$ & 0.76 \\
\hline \multirow[t]{4}{*}{$\mathrm{cT} / \mathrm{MRF}$} & cT3, MRF- & 2.24 & $(0.79 ; 6.33)$ & 0.13 & 1.52 & $(0.78 ; 2.93)$ & 0.22 \\
\hline & cT3, MRF+ & 2.24 & $(0.58 ; 8.57)$ & 0.24 & 1.42 & $(0.62 ; 3.19)$ & 0.40 \\
\hline & cT4a & 11.58 & $(2.40 ; 55.8)$ & 0.002 & 4.63 & $(1.55 ; 13.9)$ & 0.006 \\
\hline & $\mathrm{cT} 4 \mathrm{~b}$ & 12.94 & $(2.62 ; 64.0)$ & 0.002 & 7.76 & $(2.82 ; 21.4)$ & $<0.001$ \\
\hline $\mathrm{cN}$ & $\mathrm{cN}+$ & 0.55 & $(0.20 ; 1.54)$ & 0.26 & 0.98 & $(0.48 ; 2.00)$ & 0.96 \\
\hline Neoadjuvant therapy & Yes & 0.91 & $(0.30 ; 2.75)$ & 0.87 & 1.56 & $(0.70 ; 3.48)$ & 0.28 \\
\hline
\end{tabular}

TaTME Transanal total mesorectal excision, $O R$ odds ratio, $C I$ confidence interval, BMI body mass index, $A S A$ American society of anesthesiologists, $A R J$ anorectal junction 
our results. Although studies show comparable OS and DFS between R-TME and L-TME. ${ }^{16,34-36}$ a recent propensity score-matched analysis showed significantly better OS and DFS in the R-TME group than in the L-TME group. ${ }^{37}$ However, this might have been caused by a relatively high rate of distant metastasis in the L-TME group, whereas the local recurrence rate was equal. Because systemic recurrence is suggested to be a mere result of the biologic behavior and tumor stage at presentation and a less relevant outcome regarding quality of surgery, the difference in OS and DFS might not be attributable to a difference in technique.

Local recurrence was present in $6.1 \%$ of L-LAR, $6.4 \%$ of R-LAR, and $5.7 \%$ of TaTME procedures. The multivariable Cox regression did not show any difference between the three techniques, indicating adequate surgical quality and safe surgery for all three minimally invasive techniques in the dedicated centers. These results are comparable with those of large randomized controlled trials comparing L-TME with open TME surgery. However, these trials did not include patients with T4 or T3 tumors that had mesorectal fascia involvement. ${ }^{2,4,5,33}$ Furthermore, we used the rectal cancer definition as proposed by D'Souza et al. ${ }^{26}$ The exclusion of "rectosigmoid", cancers could have led to the inclusion of relatively more low rectal cancers, and therefore to more difficult tumors because this is a known risk factor for local recurrence. ${ }^{38}$

Recently, local recurrence rates after TaTME in Norway were reported to be $9.5 \%$, and a significant proportion of multifocal recurrences were reported, leading to a nationwide halt of TaTME. ${ }^{14}$ Similar results were seen in the initial cases of centers learning the TaTME technique in the Netherlands. ${ }^{15}$ However, higher local recurrence rates also have been reported in the initial cases of R-TME and L-TME. $^{16,39}$ Although these studies suggest higher local recurrence rates during the learning curve, our results showed that adequate oncologic results can be obtained for L-LAR, R-LAR, and TaTME in experienced centers after fulfilment of the learning curve, in accordance with other series. ${ }^{19,20,40}$ Furthermore, no increased rate of multifocal recurrences was observed. Earlier reports on local recurrence after R-TME describe lower rates, but these retrospective cohorts had short follow-up times, with younger patients, lower BMI, and lower rates of neoadjuvant therapy than our cohort, which may suggest selection bias in these studies. ${ }^{18,35,37,41-43}$

Certain limitations of this study should be taken into account. First, this was a retrospective cohort study. Therefore, a certain degree of bias was present. However, we tried to overcome confounding by indication, using multivariable analysis to control for baseline characteristics that might have influenced the choice for a certain surgical technique preoperatively. Our primary aim was to assess whether surgical technique would influence oncologic outcomes for TME. Therefore, we took into account only preoperative variables and did not control for postoperative variables such as pathologic TNM stage or positive circumferential resection margins because these postoperative variables are a result of the surgical technique.

Preferably, a prospective randomized controlled trial should be performed to evaluate the three minimally invasive procedures. In practice, however, randomization is hard to achieve because it can be doubted whether surgeons could be equally trained in each technique. Therefore, this population-based cohort was possibly a suitable alternative providing the current state of surgical practice with high external validity, in contrast to randomized controlled trials showing mostly low external validity due to strict inclusion and exclusion criteria. Nevertheless, because this was a retrospective cohort, the results should be replicated in a prospective study.

Second, because the surgical techniques were performed in dedicated centers, the institution itself could have influenced the outcomes as well. Adjustments could not be made for culture-, surgeon-, or team-related factors. However, by including more than one center per group, we tried to reduce this effect.

Third, we chose to select only patients who underwent a TME and excluded patients who underwent an APR. The patients who required an APR in a dedicated TaTME center underwent either a laparoscopic or an open APR because an APR is not an indication for the TaTME technique in the current Dutch clinical practice. Because we were interested in comparing the robot-assisted technique with the laparoscopic and TaTME techniques, in order to create homogeneous groups we decided to exclude patients who needed an APR. However, because APR is associated with worse oncologic outcomes, this might have influenced outcomes. Nevertheless, by excluding APR in all three groups, we tried to reduce confounding.

Finally, although we included only patients who underwent a minimally invasive TME at a dedicated center in which the learning curve had been fulfilled, the difference in experience could not be reduced to nil. The 10-year experience of the laparoscopic surgeons still exceeded the 3- to 5-year experience of the robot-assisted and TaTME surgeons.

Despite these limitations, this is the first study to show good and comparable oncologic results between R-LAR , L-LAR, and TaTME in centers with profound experience using the specific technique. All three techniques showed adequate $\mathrm{OS}$ and DFS rates. Moreover, the recurrence rates are equal between the three minimally invasive techniques when performed by experienced surgeons, and multifocal recurrence rates are low. Therefore, oncologic safety can be achieved with all three minimally invasive techniques 
when performed by experienced surgeons. Prospective cohort studies comparing oncologic outcomes after fulfillment of the learning curve are needed to confirm our results.

DISCLOSURE Crolla, Verheijen, and Consten receive fees from Intuitive Surgical. No funding was received for this study. There are no conflicts of interest.

OPEN ACCESS This article is licensed under a Creative Commons Attribution 4.0 International License, which permits use, sharing, adaptation, distribution and reproduction in any medium or format, as long as you give appropriate credit to the original author(s) and the source, provide a link to the Creative Commons licence, and indicate if changes were made. The images or other third party material in this article are included in the article's Creative Commons licence, unless indicated otherwise in a credit line to the material. If material is not included in the article's Creative Commons licence and your intended use is not permitted by statutory regulation or exceeds the permitted use, you will need to obtain permission directly from the copyright holder. To view a copy of this licence, visit http://creativecommons. org/licenses/by/4.0/.

\section{REFERENCES}

1. Heald RJ, Ryall RDH. Recurrence and survival after total mesorectal excision for rectal cancer. Lancet. 1986;327:1479-82. https://doi.org/10.1016/S0140-6736(86)91510-2.

2. Fleshman J, Branda ME, Sargent DJ, et al. Disease-free survival and local recurrence for laparoscopic resection compared with open resection of stage II to III rectal cancer: follow-up results of the ACOSOG Z6051 randomized controlled trial. Ann Surg. 2019;269:589-95. https://doi.org/10.1097/SLA.0000000000003 002 .

3. Stevenson ARL, Solomon MJ, Brown CSB, et al. Disease-free survival and local recurrence after laparoscopic-assisted resection or open resection for rectal cancer: The Australasian Laparoscopic Cancer of the Rectum randomized clinical trial. Ann Surg. 2019;269:596-602. https://doi.org/10.1097/SLA.0000000000003 021.

4. Jeong SY, Park JW, Nam BH, et al. Open versus laparoscopic surgery for mid-rectal or low-rectal cancer after neoadjuvant chemoradiotherapy (COREAN trial): survival outcomes of an open-label, non-inferiority, randomised controlled trial. Lancet Oncol. 2014;15:767-74. https://doi.org/10.1016/S1470-2045(14) 70205-0.

5. Bonjer HJ, Deijen CL, Abis GA, et al. A randomized trial of laparoscopic versus open surgery for rectal cancer. $N$ Engl J Med. 2015;372:1324-32. https://doi.org/10.1056/NEJMoa1414882.

6. Vennix S, Pelzers L, Bouvy N, et al. Laparoscopic versus open total mesorectal excision for rectal cancer. Cochrane Database Syst Rev. 2014. https://doi.org/10.1002/14651858.CD005200.pub 3.

7. DCRA. DCRA Jaarverslag 2018. Retrieved 19 August 2019 at https://dica.nl/jaarrapportage-2018/dcra. Published 2018.

8. Grass JK, Perez DR, Izbicki JR, Reeh M. Systematic review analysis of robotic and transanal approaches in TME surgery: a systematic review of the current literature in regard to challenges in rectal cancer surgery. Eur J Surg Oncol. Retrieved 3 May 2019 at https://www.sciencedirect.com/science/article/pii/S074879831 832003.1?via\%3Dihub. Published April 1, 2018.
9. Bhangu A, Minaya-Bravo AM, Gallo G, et al. An international multicentre prospective audit of elective rectal cancer surgery: operative approach versus outcome, including transanal total mesorectal excision (TaTME). Color Dis. 2018;20:33-46. http s://doi.org/10.1111/codi.14376.

10. Corrigan N, Marshall H, Croft J, Copeland J, Jayne D, Brown J. Exploring and adjusting for potential learning effects in ROLARR: a randomised controlled trial comparing robotic-assisted vs standard laparoscopic surgery for rectal cancer resection. Trials. 2018;19:339. https://doi.org/10.1186/s13063-0 18-2726-0.

11. Jayne D, Pigazzi A, Marshall H, et al. Effect of robotic-assisted vs conventional laparoscopic surgery on risk of conversion to open laparotomy among patients undergoing resection for rectal cancer. JAMA. 2017;318:1569. https://doi.org/10.1001/jama.201 7.7219.

12. Kim MJ, Park SC, Park JW, Chang HJ, Kim DY, Nam BH, et al. Robot-assisted versus laparoscopic surgery for rectal cancer: a Phase II open label prospective randomized controlled trial. Ann Surg. 2018;267(2):243-51. https://doi.org/10.1097/SLA.00000 00000002321.

13. Jiménez Rodríguez RM, Díaz Pavón JM, de La Portilla de Juan F, Prendes Sillero E, Hisnard Cadet Dussort JM, Padillo J. Prospective randomised study: robotic-assisted versus conventional laparoscopic surgery in colorectal cancer resection. Cir Esp. 2011;89:432-8. https://doi.org/10.1016/j.ciresp.2011.01. 017.

14. Wasmuth HH, Færden AE, Myklebust T, et al. Transanal total mesorectal excision for rectal cancer has been suspended in Norway. Br J Surg. 2020;107:121-30. https://doi.org/10.1002/b js. 11459 .

15. van Oostendorp SE, Belgers HJ, Bootsma BT, Hol JC, Belt EJTH, Bleeker W, et al. Locoregional recurrences after transanal total mesorectal excision of rectal cancer during implementation. Br J Surg. 2020;107(9):1211-20. https://doi.org/10.1002/bjs. 11525.

16. Polat F, Willems LH, Dogan K, Rosman C. The oncological and surgical safety of robot-assisted surgery in colorectal cancer: outcomes of a longitudinal prospective cohort study. Surg Endosc. 2019;33:3644-55. https://doi.org/10.1007/s00464-018-0 6653-2.

17. Kim NK, Kim YW, Cho MS. Total mesorectal excision for rectal cancer with emphasis on pelvic autonomic nerve preservation: expert technical tips for robotic surgery. Surg Oncol. 2015;24:172-80. https://doi.org/10.1016/j.suronc.2015.06.012.

18. Park EJ, Cho MS, Baek SJ, et al. Long-term oncologic outcomes of robotic low anterior resection for rectal cancer. Ann Surg. 2015;261:129-37. https://doi.org/10.1097/SLA.0000000000000 613.

19. Hol JC, van Oostendorp SE, Tuynman JB, Sietses C. Long-term oncological results after transanal total mesorectal excision for rectal carcinoma. Tech Coloproctol. 2019;23:903-11. https://doi. org/10.1007/s10151-019-02094-8.

20. Roodbeen SX, Spinelli A, Bemelman WA, Di Candido F, Cardepont M, Denost Q, et al. Local recurrence after transanal total mesorectal excision for rectal cancer: a multicenter cohort study. Ann Surg. 2021;274(2):359-66. https://doi.org/10.1097/S LA.0000000000003757.

21. von Elm E, Altman DG, Egger M, Pocock SJ, Gøtzsche PC, Vandenbroucke JP. The Strengthening the Reporting of Observational Studies in Epidemiology (STROBE) statement: guidelines for reporting observational studies. J Clin Epidemiol. 2008;61:344-9. https://doi.org/10.1016/j.jclinepi.2007.11.008.

22. Kim HJ, Choi G-SS, Park JS, Park SY. Multidimensional analysis of the learning curve for robotic total mesorectal excision for rectal cancer: lessons from a single surgeon's experience. Dis 
Colon Rectum. 2014;57:1066-74. https://doi.org/10.1097/DCR. 0000000000000174.

23. Jimenez-Rodriguez JM, Diaz-Pavon JM, De La Portilla F, Prendes-Sillero E, Padillo Ruiz J. Learning curve for robotic rectal cancer surgery. Color Dis. 2012;14:13. https://doi.org/10. 1111/j.1463-1318.2012.03155.x.

24. Koedam TWA, Veltcamp Helbach M, van de Ven PM, et al. Transanal total mesorectal excision for rectal cancer: evaluation of the learning curve. Tech Coloproctol. 2018;22:279-87. http s://doi.org/10.1007/s10151-018-1771-8.

25. Lee L, Kelly J, Nassif GJ, DeBeche-Adams TC, Albert MR, Monson JRTT. Defining the learning curve for transanal total mesorectal excision for rectal adenocarcinoma. Surg Endosc Other Interv Tech. 2018. https://doi.org/10.1007/s00464-018-63 60-4.

26. D'Souza N, de Neree Tot Babberich MPM, d'Hoore A, Tiret E, Xynos E, Beets-Tan RGH, et al. Definition of the rectum: an international, expert-based Delphi consensus. Ann Surg. 2019;270(6):955-9. https://doi.org/10.1097/SLA.0000000000003 251.

27. Landelijke Werkgroep Gastro Intestinale Tumoren. Richtlijn Colorectaal Carcinoom 4.0. Retrieved 13 January 2020 at https:// www.oncoline.nl/colorectaalcarcinoom. Published 2019.

28. Georgiou PA, Tekkis PP, Constantinides VA, et al. Diagnostic accuracy and value of magnetic resonance imaging (MRI) in planning exenterative pelvic surgery for advanced colorectal cancer. Eur J Cancer. 2013;49:72-81. https://doi.org/10.1016/j.e jca.2012.06.025.

29. Moran BJ, Holm T, Brannagan G, et al. The English National Low Rectal Cancer Development Programme: key messages and future perspectives. Color Dis. 2014;16:173-8. https://doi.org/10. 1111/codi.12501.

30. Nagtegaal ID, Van de Velde CJH, Van Der Worp E, Kapiteijn E, Quirke P, Van Krieken JHJM. Macroscopic evaluation of rectal cancer resection specimen: clinical significance of the pathologist in quality control. J Clin Oncol. 2002;20:1729-34. https://doi. org/10.1200/JCO.2002.07.010.

31. Dindo D, Demartines N, Clavien P-A. Classification of surgical complications. Ann Surg. 2004;240:205-13. https://doi.org/10.1 7116/hirurgia2018090162.

32. Rahbari NN, Weitz J, Hohenberger W, Heald RJ, Moran B, Ulrich A, et al. Definition and grading of anastomotic leakage following anterior resection of the rectum: a proposal by the International Study Group of Rectal Cancer. Surgery. 2010;147(3):339-51. https://doi.org/10.1016/j.surg.2009.10.012.

33. Stevenson A, Solomon M, Lumley JWJ, et al. Effect of laparoscopic-assisted resection vs open resection on pathological outcomes in rectal cancer: the ALaCaRT Randomized Clinical
Trial. J Am Med Assoc. 2015;314:1356-63. https://doi.org/10.10 01/jama.2015.12009.

34. Park JS, Kim NK, Kim SH, et al. Multicentre study of robotic intersphincteric resection for low rectal cancer. Br J Surg. 2015;102:1567-73. https://doi.org/10.1002/bjs.9914.

35. Cho MS, Baek SJ, Hur H, et al. Short- and long-term outcomes of robotic versus laparoscopic total mesorectal excision for rectal cancer. Med United States. 2015;94:e522. https://doi.org/10.109 7/MD.0000000000000522.

36. Kim J, Baek S-J, Kang D-W, et al. Robotic resection is a good prognostic factor in rectal cancer compared with laparoscopic resection: long-term survival analysis using propensity scorematching. Dis Colon Rectum. 2017;60:266-73. https://doi.org/10. 1097/DCR.0000000000000770.

37. Tejedor P, Sagias F, Flashman K, et al. The impact of robotic total mesorectal excision on survival of patients with rectal cancer: a propensity-matched analysis. Int J Colorectal Dis. 2019;34:2081-9. https://doi.org/10.1007/s00384-019-03417-9.

38. Kusters M, Marijnen CAM, van de Velde CJH, et al. Patterns of local recurrence in rectal cancer; a study of the Dutch TME trial. Eur J Surg Oncol. 2010;36:470-6. https://doi.org/10.1016/j.ejso. 2009.11.011.

39. Kim CH, Kim HJ, Huh JW, Kim YJ, Kim HR. Learning curve of laparoscopic low anterior resection in terms of local recurrence. $J$ Surg Oncol. 2014;110:989-96. https://doi.org/10.1002/jso.23757.

40. González-Abós C, de Lacy FB, Guzmán Y, et al. Transanal total mesorectal excision for stage II or III rectal cancer: pattern of local recurrence in a tertiary referral center. Surg Endosc. 2021;1:3. https://doi.org/10.1007/s00464-020-08200-4.

41. Baek JH, McKenzie S, Garcia-Aguilar J, Pigazzi A. Oncologic outcomes of robotic-assisted total mesorectal excision for the treatment of rectal cancer. Ann Surg. 2010;251:882-6. https://doi. org/10.1097/SLA.0b013e3181c79114.

42. Pigazzi A, Luca F, Patriti A, et al. Multicentric study on robotic tumor-specific mesorectal excision for the treatment of rectal cancer. Ann Surg Oncol. 2010;17:1614-20. https://doi.org/10.12 45/s10434-010-0909-3.

43. Baik SH, Kim NK, Lim DR, Hur H, Min BS, Lee KY. Oncologic outcomes and perioperative clinicopathologic results after robotassisted tumor-specific mesorectal excision for rectal cancer. Ann Surg Oncol. 2013;20:2625-32. https://doi.org/10.1245/s10434-0 13-2895-8

Publisher's Note Springer Nature remains neutral with regard to jurisdictional claims in published maps and institutional affiliations. 